\title{
Alternation responding following nonreinforcement (Eo) in 2-choice probability learning as a function of instructed interpretations of $\mathbf{E}_{\mathbf{0}}$ '
}

JOHN KOEHLER, JR.

UNIVERSITY OF ALABAMA

With the contingent event probabilities of $\pi_{1}=\pi_{2}=.50$, altermating response choices across the $\mathrm{E}_{0}$ event was investigated as a function of the two interpretations of this event, namely a wrong prediction or a blank trial. Groups receiving both interpretations of $\mathrm{E}_{o}$ showed some tendency to alternate choices across $E_{0}$. Groups instructed with a single or neither interpretation displayed a tendency to repeat the $E_{0}$-trial choice on the next trial, which for the group given wrong-prediction instructions reached a significant level in the first 40 trials. However, the latter result differed markedly from the altemation tendency across the wrong-prediction $\mathrm{E}_{\mathrm{o}}$ found in a treatment group which had individual $\mathrm{E}_{o}$ 's designated as either wrong predictions or blank trials during training. No satisfactory explanation for this discrepancy could be given.

The present report considers sequential responding across $E_{o}$ in the first 80 trials of a study where the reinforcement probabilities of $A_{1}$ and $A_{2}$ responses, denoted $\pi_{1}$ and $\pi_{2}$ respectively, were both set at .50 . Here the scheduling was arranged so that the reinforcing events followed only their respective responses. Consequently, when $\mathrm{E}_{\mathrm{o}}$ came after a response, the outcome of the alternative, non-predicted choice could not be known. In previous research, this writer (Koehler, 1961) found choice frequencies to vary predictably with pretraining instructions which designated how S should interpret the $E_{O}$ event. The present work explores the possibility that sequential choice responding across $\mathrm{E}_{\mathrm{O}}$ also varies with $E_{o}$ interpretations since the effects of this event should be strongest on the trial following its occurrence.

To this writer's knowledge, there are no published data on sequential responding in the contingent reinforcement situation, probably because probabilistic models cannot easily distinguish sequential response dependencies from other influence on choice responding in this situation (cf., Anderson, 1959, p. 258). By having $\pi_{1}=\pi_{2}=$ .50 , however, there should be little problem in interpreting the relative effects of instructions on sequential responding across $\mathrm{E}_{\mathrm{O}}$ if, as expected, choice frequencies remain near $50 \%$ over the 80 -trial series.

Information on sequential responding across $\mathrm{E}_{\mathrm{O}}$ was obtained with the following five treatments applied to separate groups of 32 Ss: (1) Group W received wrongprediction instructions about $E_{O}$; (2) Group $B$, blanktrial instructions; (3) Group WB, both wrong-prediction and blank-trial instructions; (4) Group WrB, the same instruction as Group WB and identification during training of individual $\mathrm{E}_{\mathrm{O}}$ events as either wrong predictions or blank trials; (5) Group C, no special treatment of the $\mathrm{E}_{\mathrm{o}}$ event.

Method

The 160 Ss were enrolled in introductory psychology classes. The Ss were run individually in a darkened room. The $S$ sat in a booth and when a signal lamp at his eye level flashed, predicted which of two lamps was set to light by closing the spring-release lever under the lamp.

Instructions given Ss of Groups W and WB regarding $E_{0}$ were the same as those in the earlier study (Koehler, 1961) and are paraphrased in the following remarks. The Ss of Group B were told that when the lamp above the lever they pulled did not light $\left(E_{O}\right)$ it meant both lamps were disconnected on that trial and could not be lighted by pulling their respective levers. The instructions to Group WrB Ss stated that when the red lamp found directly below the signal light flashed following a lever response, it meant the other lever should have been chosen since its lamp was set to go on. For the remaining $E_{O}$ occurrences, the Ss of this group were instructed to treat them as blank trials. No $E_{O}$ instructions were given Group C.

All groups also received the standard prediction situation instructions and with the exception of Group WrB, were told to ignore the red lamp below the signal light. After reading the instructions, the $\mathrm{E}$ asked the $\mathrm{S}$ to describe the instructions in his own words. Any apparent misunderstanding was clarified by paraphrasing the relevant parts.

The automatically-controlled temporal sequence on each trial went as follows: 1.5 sec for the signal lamp flash; 1 sec for either a lever lamp flash, a red lamp flash, or all lamps to stay dark; 1 sec darkness until next signal lamp flash. All experimental events and responses were automatically recorded. Pairs of reinforcement sequences were constructed by randomly designating half of each 10 successive $A_{1}$ and $A_{2}$ responses to be followed by their respective lamps glowing. For Group $\mathrm{WrB}$, the red lamp flashed on a random 50 percent of 10 successive $E_{o}$ events occurring with each response. Eight Ss of the 32 assigned to each instructions group received a different pair of reinforcement sequences, and sequence pairs were kept orthogonal to instructions.

Resulis

The proportions of alternating choices after $\mathrm{E}_{\mathrm{O}}$, designated $P\left(A_{j, n+1} \mid A_{i, n}, E_{o, n}\right)$, are presented in Table 1 for 
Table 1. $A_{j, n+1} \mid A_{i, n} E_{o, n}$ and $A_{1}$ Proportions

\begin{tabular}{lcccc}
\multicolumn{1}{c}{ Group } & $P\left(A_{i, n+1} \mid A_{i, n} E_{0, n}\right) P\left(A_{1}\right)$ & $P\left(A_{i, n+1} \mid A_{i, n} E_{0, n}\right) P\left(A_{1}\right)$ \\
\hline Wrong (W) & $.397 * *$ & .494 & .444 & .502 \\
Blank (B) & .485 & .500 & $.437 *$ & .476 \\
W-B & .478 & .505 & .527 & .466 \\
Control & .479 & .497 & .460 & .465 \\
W-r-B & .506 & .488 & .470 & .474 \\
Wrong $E_{0}$ & .522 & & .502 & \\
Blank $E_{0}$ & .495 & & .436 & \\
\hline
\end{tabular}

Note-Significant $t$ values for the $P\left(A_{j, n+1} \mid A_{i, n} E_{0, n}\right)$ deviation from .50 are indicated with the standard asterisk notation.

$* p<.05$

${ }^{* *} p<.01$

each of the instructions groups. Separate entries for the two types of $\mathrm{E}_{\mathrm{O}}$ events used in the Group WrB condition are also listed in the table as Wrong $E_{O}$ and Blank $E_{O}$. Each $P\left(A_{j, n+1} \mid A_{i, n}, E_{o, n}\right)$ in the table was obtained by pooling frequency scores over $\mathrm{Ss}$, both choice responses and blocks of 40 trials. As an indication of the equality of choice frequencies, the proportion of left lever responses are also given in the table under $P\left(A_{1}\right)$.

In the present work with $\pi_{1}=\pi_{2}=.50$, a deviation of $P\left(A_{j, n+1} \mid A_{i, n} E_{o, n}\right)$ from .50 denotes a sequential response effect across $E_{O}$. The differences between these proportions and .50 were evaluated by finding a $t$ on the equivalent 32 raw frequency scores of each treatment group. For these ts, whose significant values are indicated in Table 1, the sampling error was estimated by pooling the within-groups sums of squares across trial blocks.

The table shows most of the $P\left(A_{j, n+1} \mid A_{i, n} E_{o, n}\right)$ to be below .50 , signifying a tendency to perseverate on the choice of the $E_{0}$ trial. This sequential effect was found to be significantly different from .50 only for Group W in Block 1 (Trials 2-40) and for Group B in Block 2 (Trials 41-80). However in the latter case, there may be some doubt about its validity since $\mathrm{P}\left(\mathrm{A}_{1}\right)$ dropped below .50 for this group, as well as others (see Table 1), in Block 2.

The table also indicates that some nonsignificant alternation responding across $E_{o}$ occurred in Groups WrB (Block 1) and WB (Block 2). In the case of Group WrB, this appeared to be related to the two types of $E_{O}$ events: alternation took place across the Wrong $E_{o}$ and perseveration across the Blank $E_{O}$. However, in a test for paired scores based on the data pooled over all 80 trials, this difference failed to reach significance, $t=$ $1.17, \mathrm{df}=31, \mathrm{p}<.25$.

Discussion

In general, the $P\left(A_{j, n+1} \mid A_{i, n} E_{o, n}\right)$ entries in Table 1 give little evidence of a recognizable pattern that will relate meaningfully to the instructions sets. There is some indication that groups given both interpretations of $E_{O}$, namely Groups $\mathrm{WrB}$ and $\mathrm{WB}$, tend to alternate, whereas those receiving a single or neither interpretation are more likely to perseverate across $E_{0}$. But this relationship would seem to be somewhat doubtful when considering that the wrong-prediction interpretation led to opposite sequential response tendencies in Groups WrB and W. Besides, alternating choices across Wrong $\mathrm{E}_{\mathrm{O}}$ in Group WrB also disagree with the results obtained on related treatment groups in a study having a noncontingent 50:50 event sequence (LaBerge, Greeno, \& Peterson, 1962). These investigators found that over the event comparable to Wrong $\mathrm{E}_{0}$, perseveration was prevalent on the early trials of a training series in those groups receiving $33 \%$ and $67 \% \mathrm{E}_{\mathrm{o}}$ trials. Thus, since a similar sequential effect was obtained under the Group W condition here, it seems that factors in the Group WrB procedure, probably unrelated to the instructions, were responsible for choice alternation across the Wrong $E_{0}$ : presently these factors are unknown.

The tendency to perseverate across $\mathrm{E}_{\mathrm{O}}$ found in several groups here has also turned up in previous work with 50:50 event sequences (Greeno \& LaBerge, 1963; LaBerge et al, 1962). In the present work, this effect may have been enhanced by the use of event sequences with short runs since response perseveration on the incorrect choice has been found to vary inversely with event run length (Goodnow \& Pettigrew, 1955). But, unfortunately, while this explanation might give a good accounting of the marked perseveration which developed in the first 40 trials under the Group $W$ condition, it would be at odds with the equivocal results obtained with the wrong-prediction interpretation of the $E_{O}$ event.

\section{References}

Anderson, N. H. An analysis of sequential dependencies. In R. R. Bush \& W. K. Estes (Eds.), Studies in mathematical learning theory. Stanford: Stanford University Press, 1959. Pp. 248-264.

Goodnow, J. J., \& Pettigrew, T. F. Effect of prior patterns of experience on strategies and learning sets. J. exp. Psychol., $1955,49,381-389$.

Greeno, J. G., \& LaBerge, S. Sequential dependencies and nonreinforcement in probability learning. J. exp. Psychol., 1963, 66, $547-552$.

Koehler, J., Jr. Role of instructions in two-choice verbal conditioning with contingent partial reinforcement. J. exp. Psychol, $1961,62,122-125$.

LaBerge, D., Greeno, J. G., \& Peterson, O. F. Nonreinforcement and neutralization of stimuli. J. exp. Psychol., 1962,63, 207-213.

\section{Note}

1. This research was supported by a grant from the University of Alabama Research Committee. 